Original Research Article

\title{
Evaluation of cardiovascular events and bleeding complications in patients of Acute Coronary Syndrome on various antiplatelet drugs: an observational study in a tertiary care center in Eastern India
}

\author{
Anurag Passi, Prashant Kumar*, Somnath Mukherjee, Priyanker Mondal, \\ Sankar Chandra Mandal
}

Department of Cardiology, IPGMER, Kolkata, West Bengal, India

Received: 10 September 2017 Accepted: 03 October 2017

*Correspondence to:

Dr. Prashant Kumar,

Email: pkumar_rims@ yahoo.com

Copyright: (C) the author(s), publisher and licensee Medip Academy. This is an openaccess article distributed under the terms of the Creative Commons Attribution NonCommercial License, which permits unrestricted noncommercial use, distribution, and reproduction in any medium, provided the original work is properly cited.

\begin{abstract}
Background: This study is to determine the clinical profile of Acute Coronary Syndrome (ACS) patients, to observe cardiovascular events in patients with ACS undergoing Percutaneous Coronary Intervention (PCI) and to evaluate the bleeding complications with various antiplatelet agents.

Methods: This hospital based observational study included patients of ACS presenting between February 2015 to August 2016 who received PCI and were on dual antiplatelet agents.

Results: Among 200 patients presenting with ACS mean age was 58.67, there was male predominance and $52.5 \%$ presented with STEMI. Cardiovascular death was seen in $2.5 \%$ patients and all cause mortality was seen in $3.5 \%$ patients. The incidence of Non-fatal myocardial infarction was more in Clopidogrel group (5\%) as compared to Prasugrel (4\%) and Ticagrelor (2\%) group. Non-fatal stroke was seen in $2 \%$ patients and incidence was similar in each of the three groups. Incidences of target vessel revascularization (TVR) and stent thrombosis were more in the Clopidogrel group as compared to Prasugrel and Ticagrelor. TIMI Major and Minor bleeding with Prasugrel was higher than clopidogrel and Ticagrelor and TIMI minimal bleeding was seen in $2 \%$ patients and was similar in all three groups.

Conclusions: Patients receiving clopidogrel has more numbers of CV death, all cause death, non-fatal MI, TVR and stent thrombosis in comparison to the groups receiving Prasugrel or Ticagrelor and on comparing Prasugrel and Ticagrelor, the two drugs are similar in efficacy but, Ticagrelor has better safety outcomes.
\end{abstract}

Keywords: Acute Coronary Syndrome, Antiplatelet drugs, Percutaneous coronary intervention

\section{INTRODUCTION}

Thrombosis caused by a ruptured or eroded atherosclerotic plaque is the usual underlying mechanism of acute coronary syndromes. ${ }^{1}$ Aspirin and heparin reduce the risk of death from cardiovascular causes, new myocardial infarction, and recurrent ischemia, but there is still a substantial risk of such events in both the short term and the long term. ${ }^{2,3}$ The important role of antiplatelet agents in the management and prevention of the complications after ACS and percutaneous coronary intervention (PCI) is related directly to the physiological events. ${ }^{4}$ Thienopyridine antiplatelet agents interfere with platelet activation and aggregation induced by ADP. There are 3 members of the thienopyridine class of antiplatelet agents currently available for clinical use: ticlopidine, clopidogrel, and the prasugrel. All 3 agents are prodrugs and require conversion to an active metabolite to exhibit an antiplatelet effect. The thienopyridine clopidogrel, the most widely used P2Y12 inhibitor, has a number of important limitations which can be partly overcome with prasugrel, a new thienopyridine agent that is more 
efficiently metabolized to its active form and whose magnitude and consistency of platelet ADP inhibition is greater than clopidogrel. ${ }^{5}$ Ticagrelor (AZD6140), the first reversibly binding oral $\mathrm{P} 2 \mathrm{Y} 12$ receptor antagonist, has the potential to address many of the limitations of thienopyridine therapy. ${ }^{6}$ Treatment with prasugrel and ticagrelor results in higher and more consistent levels of platelet inhibition than standard- or higher-dose clopidogrel. $^{7,8}$

From the Indian perspective, there is an inherent dearth of data regarding anti-platelet treatment strategies used and related outcomes in ACS patients due to variation in antiplatelet treatment patterns and outcomes. This study collected and evaluated the effect of various anti-platelet drugs and their safety outcomes in patients of ACS undergoing Percutaneous Coronary Intervention.

\section{METHODS}

This hospital based observational study included patients of Acute Coronary Syndrome (STEMI, NSTEMI or unstable angina) aged between 18-75 years; who had undergone PCI and were on dual antiplatelet drugs between February2015 to August2016. Patients with Acute Coronary Syndrome who were on medical management or had undergone $\mathrm{CABG}$, active pathological bleeding (Ex. Peptic ulcers, Severe hepatic failure), simultaneous use of fibrinolytics, allergic reaction to active compounds, CKD patients with eGFR $\leq 30$, Age $\geq 75$ years were excluded. Informed consents were taken from all the patients and the ethics committee approval was obtained prior to study initiation.

\section{Statistical analysis}

For statistical analysis data were entered into a Microsoft excel spreadsheet and then analyzed by SPSS 20.0.1 and GraphPad Prism version 5. Data had been summarized as mean and standard deviation for numerical variables and count and percentages for categorical variables. Twosample t-tests for a difference in mean involved independent samples or unpaired samples. Paired t-tests were a form of blocking and had greater power than unpaired tests. One-way analysis of variance (one-way ANOVA) was a technique used to compare means of three or more samples for numerical data (using the $\mathrm{F}$ distribution). A chi-squared test ( $\chi^{2}$ test) was any statistical hypothesis test wherein the sampling distribution of the test statistic is a chi-squared distribution when the null hypothesis is true. Without other qualification, 'chisquared test' often is used as short for Pearson's chisquared test. Unpaired proportions were compared by Chisquare test or Fischer's exact test, as appropriate. Explicit expressions that can be used to carry out various t-tests are given below. In each case, the formula for a test statistic that either exactly follows or closely approximates a tdistribution under the null hypothesis is given. Also, the appropriate degrees of freedom are given in each case. Each of these statistics can be used to carry out either a one-tailed test or a two-tailed test. Once a $\mathrm{t}$ value is determined, a p-value can be found using a table of values from Student's t-distribution. If the calculated p-value was below the threshold chosen for statistical significance (usually the 0.10 , the 0.05 , or 0.01 level), then the null hypothesis was rejected in favour of the alternative hypothesis. p-value $\leq 0.05$ was considered for statistically significant.

\section{RESULTS}

Among total 200 patients presenting with acute coronary syndrome mean age was $58.67 \pm 10.41$, there was male predominance $(66.5 \%)$ and most of them presented with STEMI (52.5\%). Age and sex were matched in three groups receiving clopidogrel, prasugrel or ticagrelor. DES was used during PCI in 187 patients $(93.5 \%)$ and BMS was used in 13 patients $(6.5 \%)$ and 62 required multi vessel PCI (31\%). 77 patients were obese with BMI $>30 \mathrm{~kg} / \mathrm{m}^{2}$ (38.5\%), 104 were hypertensive $(52 \%), 73$ were diabetic (36.5\%), 92 were hyperlipidemic (46\%), 82 subjects were smokers $(41 \%), 38$ patients had family history of CAD (19\%), 27 patients had past history of myocardial infarction $(13.5 \%), 30$ patients had $\mathrm{CrCL}<60 \mathrm{ml} / \mathrm{min}$ $(15 \%)$.

Baseline characteristics of the patients of ACS undergoing PCI according to different types of antiplatelet drugs are described in Table 1.

Cardiovascular death was seen in 5 patients $(2.5 \%)$ among total 200 ACS admissions who underwent PCI (3\%, $2 \%$ and $2 \%$ in clopidogrel, prasugrel and ticagrelor group respectively) and all cause mortality was seen in 7 patients $(3.5 \%)(4 \%, 4 \%$ and $2 \%$ in the clopidogrel, prasugrel and ticagrelor group respectively).

Non fatal myocardial infarction was seen in 8 patients (4\%). Though the incidence of Non-fatal MI was more in Clopidogrel group as compared to Prasugrel and Ticagrelor group but the difference was not statistically significant. Non-fatal stroke was seen in 4 patients $(2 \%)$ and incidence was similar in each of the three groups. TVR (target vessel revascularization) within one year of PCI was seen in 4 patients $(2 \%)$ and stent thrombosis was seen in 6 patients $(3 \%)$. Incidences of TVR and stent thrombosiswere more in the Clopidogrel group as compared to Prasugrel and Ticagrelor group but the difference was not statistically significant (Table 2).

TIMI major bleeding was seen in 4 patients $(2 \%)(2 \%, 4 \%$ and $0 \%$ in clopidogrel, prasugrel and ticagrelor group respectively) and TIMI minor bleeding was seen in 6 patients $(3 \%)(3 \%, 4 \%$ and $2 \%$ in clopidogrel, prasugrel and ticagrelor group respectively). TIMI major and minor bleeding with Prasugrel was higher than clopidogrel and Ticagrelor but the difference was not statistically significant. TIMI minimal bleeding was seen in 4 patients (2\%) and was similar in all three groups. 
Table 1: Base line characteristics of patients of ACS undergoing PCI according to the different types of antiplatelet intake.

\begin{tabular}{|c|c|c|c|c|}
\hline & Clopidogrel & Prasugrel & Ticarelor & Total \\
\hline Number of patients & 100 & 50 & 50 & 200 \\
\hline Mean age (years) & 58.92 & 59.46 & 57.40 & 58.68 \\
\hline \multicolumn{5}{|l|}{ SEX } \\
\hline male & 65 & 34 & 34 & 133 \\
\hline female & 35 & 16 & 16 & 67 \\
\hline \multicolumn{5}{|l|}{ Types of ACS } \\
\hline STEMI & 52 & 25 & 28 & 105 \\
\hline NSTEMI & 18 & 8 & 8 & 34 \\
\hline UA (Unstable Angina) & 30 & 17 & 14 & 61 \\
\hline \multicolumn{5}{|l|}{ BMI (Body Mass Index) } \\
\hline$<30 \mathrm{Kg} / \mathrm{m}^{2}$ & 63 & 29 & 31 & 123 \\
\hline$>30 \mathrm{Kg} / \mathrm{m}^{2}$ & 37 & 21 & 19 & 77 \\
\hline \multicolumn{5}{|l|}{ Hypertension } \\
\hline yes & 50 & 28 & 26 & 104 \\
\hline no & 50 & 22 & 24 & 96 \\
\hline \multicolumn{5}{|l|}{ Diabetes Mellitus } \\
\hline yes & 38 & 18 & 17 & 73 \\
\hline no & 62 & 32 & 33 & 127 \\
\hline \multicolumn{5}{|l|}{ Hyperlipidemia } \\
\hline yes & 45 & 23 & 24 & 92 \\
\hline no & 55 & 27 & 26 & 108 \\
\hline \multicolumn{5}{|l|}{ Smoking } \\
\hline yes & 41 & 21 & 20 & 82 \\
\hline no & 59 & 29 & 30 & 118 \\
\hline \multicolumn{5}{|c|}{ Family history of Coronary Artery Diseases } \\
\hline yes & 20 & 10 & 8 & 38 \\
\hline no & 80 & 40 & 42 & 162 \\
\hline \multicolumn{5}{|c|}{ Past history of Myocardial Infarction } \\
\hline yes & 14 & 8 & 5 & 27 \\
\hline no & 86 & 42 & 45 & 173 \\
\hline \multicolumn{5}{|l|}{ Creatinine clearance } \\
\hline$<60 \mathrm{ml} / \mathrm{min}$ & 14 & 8 & 8 & 30 \\
\hline$>60 \mathrm{ml} / \mathrm{min}$ & 86 & 42 & 42 & 170 \\
\hline \multicolumn{5}{|l|}{ STENT used } \\
\hline BMS & 7 & 3 & 3 & 13 \\
\hline DES & 93 & 47 & 47 & 187 \\
\hline \multicolumn{5}{|c|}{ Multi-vessel PCI (percutaneous coronary intervention) } \\
\hline yes & 33 & 15 & 14 & 62 \\
\hline no & 67 & 35 & 36 & 138 \\
\hline
\end{tabular}

Table 2: Outcome of ACS patients undergoing PCI according to intake of different types of antiplatelet intake.

\begin{tabular}{|llllll|}
\hline & Clopidogrel & Prasugrel & Ticagrelor & Total & P-value \\
\hline Cardio-Vascular death & 3 & 1 & 1 & 5 & 0.9025 \\
\hline All cause death & 4 & 2 & 1 & 7 & 0.8009 \\
\hline Non fatal Myocardial Infarction & 5 & 2 & 1 & 8 & 0.6766 \\
\hline Non fatal stroke & 2 & 1 & 1 & 4 & 1.000 \\
\hline Target vessel revascularisation & 3 & 1 & 0 & 4 & 0.4652 \\
\hline Stent thrombosis & 4 & 1 & 1 & 6 & 0.7092 \\
\hline TIMI major bleeding & 2 & 2 & 0 & 4 & 0.4652 \\
\hline TIMI minor bleeding & 3 & 2 & 1 & 6 & 0.8421 \\
\hline TIMI minimal bleeding & 2 & 1 & 1 & 4 & 1.000 \\
\hline
\end{tabular}




\section{DISCUSSION}

Among the total 200 patients presenting with acute coronary syndrome, the mean age was $58.67 \pm 10.41$ which is comparable to other studies done in India, that is, CREATE registry ( $56 \pm 13$ years), Jose and Gupta study (57 \pm 12 years) and study by Sharma (54.71 \pm 19.90 years) but lower than the western population as in COURAGE trial (62 \pm 5 years). ${ }^{9-11}$ The skewed gender distribution towards male $(66.5 \%)$ in our study can be attributed to the gender bias and atypical presentation, which is also a feature in Interheart study and its South Asian cohort (overall male, $76 \%$ and South Asian cohort, 85\%). ${ }^{12}$ Patients in India who have acute coronary syndromes have a higher rate of STEMI than do patients in developed countries which is also seen in CREATE registry and Sharma study. In our study also the most common presentation among ACS patients is STEMI (52.5\%) whereas in reports from developed countries including the European Heart Surveys, fewer than $40 \%$ had STEMI. ${ }^{13-17}$

The prevalence of obese patients was $38.5 \%$ which was less than the prevalence seen in South Asian cohort of INTERHEART study $(44.2 \%){ }^{12}$ The prevalence of hypertension in South Asian cohort of INTERHEART study $(31.1 \%)$ was comparatively lower than in our study $(52 \%)$ but near to other Indian studies like CREATE registry $(37.7 \%)$, Jose and Gupta study. ${ }^{9,10}$ In the present study the prevalence of diabetes was $36.5 \%$, which was higher than the prevalence reported in the CREATE Registry (30.4\%), and in a similarly aged population from (10.5\%) South Asian countries in the INTERHEART study. The higher prevalence of diabetes and hypertension could be explained by the comparatively higher development and increasing epidemic of CAD in India. ${ }^{18}$ Dyslipidemia was found in $46 \%$ of this study population which was less than seen in TRITON-TIMI 38 Trial (56\%) and PLATO trial $(46.6 \%) .{ }^{19,20}$ The prevalence of tobacco smoking was high in the present study (41\%) comparable to CREATE Registry(40.2\%) and study by Sharma et al $(49 \%) .{ }^{21}$ In CREATE REGISTRY and TRITON TIMI 38 Trial, the prevalence of patients with past history of myocardial infarction was $17.5 \%$ and $18 \%$ respectively and in study by Yadav et al, family history of coronary artery disease was there in $14 \% .{ }^{21}$ DES was used during PCI in 187 patients $(93.5 \%)$ and BMS was used in 13 patients $(6.5 \%)$. In TRITON-TIMI 38 Trial, BMS was used in $47.5 \%$ and DES was used in $48 \%$. Incidence of multi vessel PCI was $31 \%$ in our study which is comparatively higher than TRITON-TIMI 38 Trial (14\%).

Cardiovascular death was seen in $2.5 \%$ patients and all cause mortality was seen in 4 patients $(2 \%$ ) (more in the clopidogrel group than prasugrel or ticagrelor). In TRITON-TIMI-38, PLATO and PRAGUE-18 trials both cardiovascular death and all cause mortality were less with prasugrel and ticagrelor than with clopidogrel.In the (GRAPE) Registry, the incidence of all cause mortality was $6.2 \%$ with clopidogrel and $2.9 \%$ with Prasugrel and Ticagrelor. ${ }^{23}$ Non fatal myocardial infarction was seen more in clopidogrel than other two groups and non-fatal stroke was similar in all three groups. In PRAGUE-18 Trial, the incidence of non-fatal myocardial infarction was $1.3 \%$ with Prasugrel and $1.2 \%$ with Ticagrelor. In TRITON-TIMI 38 Trial, the incidence of non-fatal myocardial infarction was $7.3 \%$ with Prasugrel vs. 9.5\% with Clopidogrel and this difference was statistically significant. In TRITON-TIMI 38 Trial, at 15 months, the incidence of non-fatal stroke was $1 \%$ with both Prasugrel and Clopidogrel. TVR (target vessel revascularization) within one year of PCI was seen in 4 patients $(2 \%)(3 \%$, $2 \%$ and $0 \%$ in clopidogrel, prasugrel and ticagrelor respectively). In TRITON-TIMI 38 Trial, GRAPE registry and PRAGUE-18 trial, incidence of Urgent target-vessel revascularization were less with Prasugrel and ticagrelor than with Clopidogrel and it was similar with Prasugrel and Ticagrelor. In TRITON-TIMI 38 Trial and PLATO trial prasugrel and ticagrelor were associated with lower incidence of Stent thrombosis than clopidogrel. In PRAGUE-18 Trial, at 1 month, the incidence of stent thrombosis was $0.5 \%$ with Prasugrel and $0.9 \%$ with Ticagrelor but the difference did not reach statistical significance. Contrary to the above studies, in this study, at 12 months, the incidence of Stent thrombosis was more in Clopidogrel (4\%) than Prasugrel $(2 \%)$ or Ticagrelor group $(2 \%)$ but the difference did not reach statistical significance.

TIMI major bleeding was seen in2\%patients and TIMI minor bleeding was seen in 3\% patients. Both were higher with Prasugrel than with clopidogrel or Ticagrelor but the difference was not statistically significant. TIMI minimal bleeding was seen in 4 patients $(2 \%)$ and was similar in all three groups. In the PLATO Trial, at 12 months, incidence of TIMI Major bleeding was $7.7 \%$ and $7.9 \%$ with clopidogrel and Ticagrelor respectively and the difference was statistically insignificant. In the TRITON TIMI 38 Trial, at the end of 15 months, patients treated with prasugrel, $146(2.4 \%)$ had at least one TIMI major hemorrhage that was not related to $\mathrm{CABG}$, as compared with 111 patients $(1.8 \%)$ treated with clopidogrel and the difference was statistically significant. Also, greater in the prasugrel group was the rate of life-threatening bleeding ( $1.4 \%$ vs. $0.9 \%$; $\mathrm{P}=0.01)$, including nonfatal bleeding ( $1.1 \%$ vs. $0.9 \%$; hazard ratio, $1.25 ; \mathrm{P}=0.23)$ and fatal bleeding ( $0.4 \%$ vs. $0.1 \%$; $\mathrm{P}=0.002)$. In PRAGUE- 18 Trial, at 1 month, the incidence of TIMI major bleeding was $0.6 \%$ with Prasugrel and $0.7 \%$ with Ticagrelor but the difference did not reach statistical significance.

\section{CONCLUSION}

Prevalence of acute coronary syndrome is on the rise all across the world. Although relative percentage of STEMI is decreasing over the last few decades in large global registries, in Indian population prevalence of STEMI is still high. Mean age of presentation of myocardial infarction is less in Indian population as compared to the western world. Use of dual anti-platelets in the form of aspirin plus P2Y12 inhibitors (clopidogrel, Prasugrel or 
ticagrelor) is recommended after ACS undergoing PCI. As far as the baseline characteristics of ACS patients are concerned, our patients had more hypertension and diabetes, in comparison to other studies, but prevalence of other risk factors like hyperlidemia, history of smoking, family history of CAD, past history of MI, depressed renal function, obesity were more or less similar. Among the subgroups, patients receiving clopidogrel has more numbers of CV death, all cause death, non-fatal MI, TVR and stent thrombosis in comparison to the groups receiving Prasugrel or ticagrelor and on comparing Prasugrel and Ticagrelor, the two drugs are similar in efficacy but, ticagrelor has better safety outcomes. Our study didn't meet the statistical significance probably due to small sample size and low power of the study.

Funding: No funding sources Conflict of interest: None declared

Ethical approval: The study was approved by the Institutional Ethics Committee

\section{REFERENCES}

1. Yeghiazarians Y, Braunstein JB, Askari A, Stone PH. Unstable angina pectoris. $N$ Engl $J$ Med. 2000;342:101-14.

2. Antiplatelet Trialists' Collaboration. Collaborative overview of randomized trials of antiplatelet therapy. I. Prevention of death, myocardial infarction, and stroke by prolonged antiplatelet therapy in various categories of patients. BMJ. 1994;308:81-106.

3. Low-molecular-weight heparin during instability in coronary artery disease. Lancet. 1996;347:561-8.

4. Antman EM, Anbe DT, Armstrong PW, Bates ER, Green LA, Hand M, et al. ACC/AHA guidelines for the management of patients with ST-elevation myocardial infarction: a report of the American College of Cardiology/American Heart Association Task Force on Practice Guidelines (Committee to Revise the 1999 Guidelines for the Management of Patients with Acute Myocardial Infarction). Circulation. 2004;110:e82-292.

5. Sugidachi A, Asai F, Ogawa T, Inoue T, Koike H. The in vivo pharmacological profile of CS-747, a novel antiplatelet agent with platelet ADP receptor antagonist properties. $\mathrm{Br} \mathrm{J}$ Pharmacol. 2000;129:1439-46.

6. Gurbel PA, Bliden KP, Butler K, Tantry US, Gesheff $\mathrm{T}$, Wei C, et al. Randomized double-blind assessment of the ONSET and OFFSET of the antiplatelet effects of ticagrelor versus clopidogrel in patients with stable coronary artery disease: the ONSET/OFFSET study. Circulation. 2009; 120:2577-85.

7. Brandt JT, Payne CD, Wiviott SD, Weerakkody G, Farid NA, Small DS, et al. A comparison of prasugrel and clopidogrel loading doses on platelet function: magnitude of platelet inhibition is related to active metabolite formation. Am Heart J. 2007;153:66:e9-16.

8. Wiviott SD, Trenk D, Frelinger AL, O'Donoghue M, Neumann FJ, Michelson AD, et al. Prasugrel compared with high loading- and maintenance-dose clopidogrel in patients with planned percutaneous coronary intervention: the Prasugrel in Comparison to Clopidogrel for Inhibition of Platelet Activation and Aggregation-Thrombolysis in Myocardial Infarction 44 trial. Circulation. 2007;116:2923-32.

9. Xavier D, Pais P, Devereaux PJ, Xie C, Prabhakaran D, Reddy KS, et al. Treatment and outcomes of acute coronary syndromes in India (CREATE): A prospective analysis of registry data. Lancet. 2008;371:1435-42.

10. Gupta R, Gupta VP. Meta-analysis of coronary heart disease prevalence in India. Indian Heart $\mathrm{J}$. 1996;48:241-5.

11. Sharma R, Bhairappa S, Prasad SR, Manjunath CN. Clinical characteristics, angiographic profile and in hospital mortality in acute coronary syndrome patients in south indian population Year. 2014;2(3):65-9.

12. Yusuf S, Hawken S, Ounpuu S, Dans T, Avezum A, Lanas $\mathrm{F}$, et al. Effect of potentially modifiable risk factors associated with myocardial infarction in 52 countries (the INTERHEART study): Case-control study. Lancet. 2004;364:937-52.

13. Hasdai D, Behar S, Wallentin L. A prospective survey of the characteristics, treatments and outcomes of patients with acute coronary syndromes in Europe and the Mediterranean basin; the Euro Heart Survey of Acute Coronary Syndromes (Euro Heart Survey ACS). Eur Heart J. 2002;23:1190-201.

14. Mandelzweig L, Battler A, Boyko V, Bueno $\mathrm{H}$, Danchin N, Filippatos G, et al. The second Euro Heart Survey on acute coronary syndromes: characteristics, treatment, and outcome of patients with ACS in Europe and the Mediterranean Basin in 2004. European heart Journal. 2006 Aug 14;27(19):2285-93.

15. Fox KA, Dabbous OH, Goldberg RJ, Pieper KS, Eagle KA, Van de Werf F, et al. Prediction of risk of death and myocardial infarction in the six months after presentation with acute coronary syndrome: prospective multinational observational study (GRACE). BMJ. 2006 Nov 23;333(7578):1091.

16. Budaj A, Brieger D, Steg PG, Goodman SG, Dabbous $\mathrm{OH}$, Fox KA, et al. Global patterns of use of antithrombotic and antiplatelet therapies in patients with acute coronary syndromes: insights from the Global Registry of Acute Coronary Events (GRACE). American Heart J. 2003 Dec 31;146(6):999-1006.

17. Fox KA, Goodman SG, Klein W, Brieger D, Steg PG, Dabbous O, et al. Management of acute coronary syndromes. Variations in practice and outcome. Findings from the Global Registry of Acute Coronary Events (GRACE). European Heart J. 2002 Aug 1;23(15):1177-89.

18. Farmer JA, Gotto AM. Dyslipidemia and other risk factors for coronary heart disease.In Braunwald E, editor. Heart Disease: A textbook of Cardiovascular Medicine. 5th edition. Philadelphia: WB Saunders; 1997:1126-1160.

19. Wiviott SD, Braunwald E, McCabe $\mathrm{CH}$, Montalescot G, Ruzyllo W, Gottlieb S, et al. Prasugrel versus 
clopidogrel in patients with acute coronary syndromes. N Engl J Med. 2007;357:2001-15.

20. Wallentin L, Becker RC, Budaj A, Cannon CP, Emanuelsson H, Held C, et al. Ticagrelor versus clopidogrel in patients with acute coronary syndromes. New England Journal of Medicine. 2009 Sep 10;361(11):1045-57.

21. Yadav P, Joseph D, Joshi P, Sakhi P, Jha RK, Gupta J. Clinical profile \& risk factors in acute coronary syndrome. National J Comm Med. 2010;1(2):150-1.

22. Motovska Z, Hlinomaz O, Miklik R, Hromadka M, Varvarovsky I, Dusek J, et al. Prasugrel Versus Ticagrelor in Patients with Acute Myocardial Infarction Treated With Primary Percutaneous Coronary Intervention. Circulation. 2016 Nov 22;134(21):1603-12.
23. Alexopoulos D, Xanthopoulou I, Deftereos S, Hamilos M, Sitafidis G, Kanakakis I, et al. Contemporary antiplatelet treatment in acute coronary syndrome patients undergoing percutaneous coronary intervention: 1-year outcomes from the GReek AntiPlatElet (GRAPE) Registry. J of Thro and Hae. 2016 Jun $1 ; 14(6): 1146-54$.

Cite this article as: Passi A, Kumar P, Mukherjee S, Mondal P, Mandal SC. Evaluation of cardiovascular events and bleeding complications in patients of Acute Coronary Syndrome on various antiplatelet drugs: an observational study in a tertiary care center in Eastern India. Int J Basic Clin Pharmacol 2017;6:2695-700. 